\title{
The Gap between Primay and Secondary School Teacher Followership Styles at Adni Islamic School, Malaysia
}

\author{
Ahmad Suhail Al-Anshory, Hairuddin Mohd. Ali"
}

\begin{abstract}
The purpose of this quantitative research was to investigate the gap between primary and secondary school teachers' followership styles at a private Islamic school in Malaysia. Questionnaire surveys were completed by 92 teachers from both respective schools. The findings of this research show that all of Kelley's Followership Styles (exemplary, alienated, pragmatist, conformist and passive) were represented in the followership styles of primary and secondary school teachers at AIS. The most common followership style is the exemplary style which was practiced by $39(42.3 \%)$ of the teachers. Furthermore, the findings show that there was a significant difference in followership styles between the male primary and secondary school teachers of AIS. However, there was no significant difference in followership styles between the female primary and secondary school teachers of AIS. In general, there was no significant difference of followership styles between both schools. Based on the findings of this study, it is recommended that the exemplary followership style be adopted, since it is especially suited to helping followers achieve exemplary levels that can help promote higher standards of organizational performance. Suggestions concerning further research on the subject of followership are also presented.
\end{abstract}

Keywords: Followership style, school leadership, organizational style, organizational performance, school management.

Kulliyyah of Education, International Islamic University Malaysia. 


\section{Introduction}

Followership is a crucial concept that is receiving more emphasis by organizational leaders. The last couple of decades have been the era of followers. According to Kelley (1992: 8), “on a global level, hundreds of thousands of Soviet, Eastern European, and African citizens have exercised the power of followership to reclaim control of their countries and their lives." Similarly, many researchers, scholars, and practitioners from diverse disciplines have created a heady discussion and acknowledged the significance of followers (Chaleff, 2009).

The term "followership" has a negative meaning to people who dislike to be categorized as such (Alcorn, 1992). John (2010) posits that recently the activities of followers in organizations are creating waves based on the fact that followers are becoming more important than ever before. Williams and Miller (2002) asserted that more than 1,600 executives across a wide range of organizations are followers in some fashion. Yet, no one concedes that they are followers. Some people believe that being a follower is second best to being a leader, while some believe that "playing second fiddle" is not as important as being in a leadership position (Ricketts, 2009).

At present, organizations demand effective followership in order to achieve the targeted performance goals. Successful followership is not solely dependent on leaders, but instead represents the quality of the symbiotic relationship between the leaders and the followers (Heremuru, 2008). Nevertheless, it is important to get more people thinking about how to create and become great followers (Bennis, 2008). Significantly, leaders should adapt a style of maximizing the capabilities of their followers. This can be made effectively when leaders are fully aware of their followers' style so that they can adjust their approach accordingly (Heremuru, 2008).

Followership styles have been discussed by Chaleff (2009), who declares that followers can be typified as resources, individualists, implementers and partners. Kelley (1992) supports this view but added five other followership styles: exemplary, alienated, conformist, pragmatist and passive. Based on these, he created a questionnaire for identifying followership styles. This questionnaire will be used in this study to investigate the followership styles among secondary and 
primary school teachers at Adni Islamic School, Malaysia. This study is hoped to benefit both followers and leaders of private and public primary and secondary schools in Malaysia.

\section{The Problem of Followership in Schools}

The landscape of followership has changed considerably in the last twenty-five years (Kelley, 1992). A number of recent studies have highlighted the importance of followership, identifying issues for leadership processes, and of leaders' capacity to shape followers' identity (Collinson, 2006). Many scholars are now increasingly aware that followership is an integral part of leadership theory and practice (Kellerman, 2008). Similarly, Donald (2010) states that in recent years, the role of 'followers' within organizations has become an important theme in theoretical, applied and empirical research in leadership and management studies.

In a consulting report by Curphy (2005), employers' expectations for work have changed over the past fortly years due to followership attitude. Cross and Parker (2004) state that the traditional organizational hierarchy between leaders and their followers has eroded over time. These changes have also taken place in the educational fields, with more international university leaders trying to emphasize the need to reevaluate the tendency to focus on leadership at the exclusion of followership (Ye, 2008).

While many studies have been conducted on followership in higher education, particularly at the university level, there are only a few studies at the secondary and primary school levels. Based on this, Ye (2008) suggests carrying out the studies at different educational levels to reassess the model that was suggested by his study. Other researchers have conducted studies on followership in non-educational settings. For instance, Burke (2009) prefers to conduct studies on followership styles of medical science liaisons within the pharmaceutical and biopharmaceutical industry. Besides, Havins (2010) has conducted research on followership behaviours in law enforcement, and meanwhile, Chai (2010) has completed his research on followership in the Presbyterian church.

Adni Islamic School (AIS) is a private Islamic school in Malaysia. AIS was established in 1994 to provide a quality integrated 
Islamic programme for children from pre-school to secondary level. It is registered with the Malaysian Ministry of Education. The school presently has over 1,000 students and 100 teachers from different countries (Adni, 2008). Furthermore, the school is expected to play a pivotal role in the development of a strong ummah based on firm Islamic values and identity by providing a holistic, quality and affordable education to all, irrespective of creed and colour. Teachers in this school come from different backgrounds and different cultures. It is also very important to investigate the followership style gap between primary and secondary school teachers at AIS so that the leaders in educational administration or leadership positions can take advantage of the findings to understand more of their followers, and their followership styles.

\section{Conceptual Framework on Followership}

Initially, followership has been defined in so many ways depending on an individual's underlying assumptions about the follower. Bresnen (1995), Bryman (1986), Collinson (2006) and Smircich and Morgan (1982) claim that 'followership' means the status of people who follow those who assume leadership roles. Kellerman (2008) defines 'followers' as subordinates who have less power, authority, and influence than their superiors. Dixon (2003) stress that a follower is not synonymous with a subordinate. Followership styles have been categorized by Kelley (1992: 87) as 'exemplary followers', 'alienated followers', 'conformist followers', 'pragmatist followers' and 'passive followers'.

Exemplary followers are those who are ideal in almost all ways, excelling at all tasks, engaging strongly with the group and providing intelligent yet sensitive support and challenge to the leader. Alienated followers are those who are deep and independent thinkers who do not willingly commit to any leader; whereas conformist followership describes those who are more participative than passive followers, but do not provide any particular challenge. In addition, pragmatist followership describes those who are middling in their independence, engagement and general contribution. Finally, passive followership, describes those who are told to do their role but do not think critically and are not particularly active participants (Kelley, 1992: 94).

Based on these definitions, teachers as followers are assumed to possess five followership styles such as 'exemplary followers', 
'alienated followers', 'conformist followers', 'pragmatist followers' and 'passive followers'.

\section{Previous Studies on Followership}

Followership study is advantageous in the field of leadership and indispensable to organizational leaders. Grint (2000: 4) stresses that "come follow go lead, represents a new focus of the studies on followership". There are many researches on followership related to Kelley's model and theory of followership styles. All these researches offer significant ideas in the ways of thinking about organizational behavior with reference to the relationship of leaders-followers in an organization.

In a past study related to Kelley's conceptual framework, Beckerleg (2002) identifies the followership style of educational leaders and relate that style to temperament and personal characteristics such as gender. The research relates and describes the role of the follower and the relationship between the leader and followers by following Kelley's conceptual framework as well as Sergiovanni's (1996) to show the importance of followership in building community in schools.

Steyer (2001) stresses that over 5,000 studies are related to leadership, while followership is not a new concept in the field of leadership study. The researcher emphasizes that there are current misconceptions of the leader-follower relationship that are inhibiting many current educational reform efforts, yet researchers have not been able to answer questions pertaining to organizational performance or effectiveness in terms of followership. The majority of such studies have focused on the leader and the leader's effects on organizational success.

The relationship between the followership-leadership characteristics was examined by Wonders (1996) who carried out a descriptive, correlational survey on 259 nurses for the purpose of exploring the relationship between nurses' perceived levels of practice, education, and reported followership-leadership characteristics. A demographic survey and the Leadership and Followership Style Test questionnaire were completed by a convenience sample who were employed by a hospital in one state in the Pacific Northwest. Relationships between the demographic data and followership, leadership, and 
followership-leadership perceived levels of practice were calculated from a magnitude rating scale. Descriptive and correlational statistics were used to determine the attributes reported by the respondents. No statistical significance was noted in any of the relationships except for followership characteristics and reported education by baccalaureate prepared nurses.

Similarly, the study by VanDoren (1998) provides an overview on the tested hypothesis that staff nurses in hospitals use different leadership and followership behaviours than staff nurses in home care settings in the Midwest. A total of 136 Multifactor Leadership Questionnaires (Bass \& Avolio, 1995) were used to measure leadership behaviours while Kelley's (1992) Followership Style Questionnaire was used to measure followership behavior; $57 \%$ of the distributed surveys were returned for data analysis.

The analysis indicate that no differences between the hospital and home care staff nurses were found. The findings provided a support for the premise that staff nurses varied in their use of transformational and transactional behaviour, compared to the previous respondents in the literature which accounts for $75 \%$ use of effective followership style, $22 \%$ use a pragmatist style, and $3 \%$ a conformist style. Thus, nurses in this sample did not adopt the alienated or passive followership styles.

Barth (2003) examines followership preferences for genderbased leadership behavioural characteristics in the virtual environment. In this research two null hypotheses were tested through the virtual environment; and there was no relationship between any of the five followership types by gender and preference for gender-based leadership behavioural characteristics and there was no difference in followers' preferred gender-based leadership behavioral characteristics, as being predominantly male or female. The research considered followership type and gender. Data were collected through an on-line survey among professionals employed by Cooperative Extension in the western United States. Original data were gathered on followers' characteristics and preferences for leadership behavioural characteristics.

Similarly, a study by Mertler(1997) determines if public teachers in the states of California and Ohio understand the role and importance of followership in influencing school leadership. The investigation through the data collected among teachers revealed that these teachers 
were aware of and understood the essential importance of followership in their roles in schools. The teachers in this study were identified as three types of followers; exemplary, pragmatist, or conformist. Subscale scores were obtained for independent thinking and active engagement. The study concluded that the female teachers reported a higher level of active engagement in this role than male teachers.

\section{Recent Developments}

A number of recent studies highlight the importance of followership in organizations and identify the issues of leadership processes and of leaders' capacity to shape followers' characters and thinking.

Pitron (2008) examined the perceptions of exemplary followership in the life experiences of 20 aerospace company performers working on a government contract maintaining post cold war era weapons systems with reduced funding. NVivo7 software was used to analyse collected data. The research question was, "Is there a perception that exemplary followership exists in an organization within the large aerospace company performing on a government contract in Florida?" The findings concluded that perceptions of exemplary followership did exist.

According to Ricketson (2008), followers provide new insights into the leader-follower relationship. Ricketson's (2008) study explored the relationship of the transformational leadership style, transactional leadership style, and laissez-faire leadership style with five dimensions of courageous followership: courage to assume responsibility, courage to serve, courage to challenge, courage to participate in transformation, and courage to take moral action. The Multifactor Leadership Questionnaire (Bass \& Avolio, 1995) was utilized to measure the leadership styles. The Follower Profile (Dixon, 2003) was utilized to measure the dimensions of courageous followership. It was found that "The literature has implied, but has not explicitly stated, that a relationship exists between leadership styles and dimensions of courageous followership" (Ricketson, 2008: 28).

The finding suggests that courageous followers behave according to their own characteristics regardless of the leadership style of the leader. Ricketson (2008) suggested that the results of this study require further research related to dimensions of courageous 
followership and how the leader-follower relationship is impacted by courageous followers.

Thus, followership style through thinking, behavior, independently or dependently, passive or active, were not only observed in schools but often observed in different organizations. However, it is important to understand that leaders are still followers in organizations.

A recent research by Aliabadizadeh (2009) investigates if there is a significant relationship between followership roles in relation to levels of organization performance by using followership traits. This research was quantitative in nature. A total of 208 employees completed the fort-part survey from different organizations, where each part was related to organization performance, to followership specific roles, to holistic personality type and to the power of followership. The findings from this research indicate that a significant positive relationship exists between followership roles and the organization performance. Similarly, the effect witnessed between the followership role and followership traits reported higher levels in organization performance.

Smith(2009)looks into postsecondary institutions where they are confronted with challenges of rising accountability, shrinking budgets, and administrative downsizing, and thus higher education leaders are expecting more from their faculty members. Smith (2009) stresses that there is an improvement in understanding that the faculty followership behaviours is increasingly important. In this context, research warrants an examination of the relationship between followership behaviors and individual variables, organizational culture, and institutional variables among Florida community college faculty. Therefore, an on-line questionnaire was distributed among the faculty and completed by 661 faculty members from 27 of Florida's 28 community colleges. Analyses reveal significant effects for age, education level, and discipline for the responsibility dimension; sex, rank, and discipline for the service dimension; age and discipline for the challenge dimension; tenure, sex, and discipline for the transformation dimension; tenure and age for the moral action dimension; and age, sex, rank, and discipline for the total followership score. Further analyses indicate significant interactions in the responsibility dimension for tenure by duration of employment and academic discipline by duration of employment; and in the service dimension for age by tenure. Significant results for organizational culture 
were found for each followership dimension except responsibility. Also, statistically significant results were found among institutional variables for the moral action dimension for degree offered, with faculty from colleges that offered bachelor's degrees scoring higher for moral action than faculty from institutions that did not offer bachelor's degrees.

Carsten, Uhl-Bien, Mary, West, Bradley, Patera, Jaime, McGregor, and Rob (2010) adopt a qualitative approach to deconstruct the meaning of followership in their study. This study conducts interviews with employees in various industries. It examines how individuals socially construct their roles as followers and explores followership schemas and contextual influences that relate to these constructions. The result from Carsten, et al.'s (2010) study suggested that some individuals were socially constructing around passivity, deference and obedience, while others emphasized the importance of constructively questioning and challenging their leaders. At the side of personal qualities for followership effectiveness, major themes such as obedience, expressing opinions, and taking initiatives were found to be most disparate across different groups of followers. In addition, the results also reveal that contextual factors may affect both followership constructions and behaviour in the follower role.

With regard to supply chain of leadership and followership, Defee (2010) develops the concepts of supply chain leadership (SCL) and supply chain followership (SCF) from the literature, and proposes a theory of leadership in supply chains using a strategy-structureperformance theory framework. Structural equation modeling was used to analyze interactive simulation data by following the SCL and SCF theoretical structural elements of information availability, communication, and rewards which were the constructs of the study. Findings show that Transformational SCL and SCF are inter-related constructs that can be linked to the creation of the three forms of supply chain structure examined in this research to varying degrees. A finding of significance also shows that supply chain follower organizations may actually have greater influence over operational performance than the supply chain leader.

Leaders as well as followers are both essential elements within the leadership process. Notgrass (2010) emphasizes that leadership has been widely studied; there has been unlimited research devoted 
to followership and its role in the leadership process. However, this quantitative study by Notgrass (2010) examined the relationship between followers' perception of quality of relationship with their leaders and followers' preferred leadership style from their leaders among 105 Certified Public Accountants working in the United States. The study's variables were measured by employing the LMX-7 questionnaire to measure followers' perception of quality of relationship with the leader and the MLQ (Form-5X) was used to measure followers' preference for transformational leadership behaviours and transactional leadership behaviours from their leader. Pearson correlation (r) and t-tests determined positive, significant levels of relationship between followers' perceived quality of relationship and followers' preference for transformational leadership style as well as between followers' perceived quality of relationship and follower's preference for the transactional leadership subscale factor of contingent reward. The study finding shows that the level of preference for transactional leadership remained relatively consistent, regardless of the quality of relationship.

Brumm (2010) investigated whether there is a relationship between leaders' long-term planning and enabling of followers. This research was carried out among employees in America to determine whether their perception of their supervisors' long-term planning behaviour showed a relationship as to how they could be influenced to be good followers or poor followers. Data were collected through online survey. Through the implementation of Pearson correlation test, strong and positive relationships between followers' perception of good longterm planning by their leaders and followers' assessment of whether they were enabled toward positive follower behaviour were found to be statistically significant. More so, statistically significant on strong and positive relationships were also found between followers' perception of poor long-term planning by their leaders and followers' assessment of whether they were influenced toward negative follower behaviour. Thus, it was found that organizational size was not a moderator of these relationships. The relationships found were correlations-no direct causation was sought or found.

Another study by Chai (2010) attempts to answer the questions "What is the nature of the relationship between congregational leadership positions and dimensions of followership styles?" and "Do certain characteristics of the participants, such as age, gender, and language 
usage, have an effect on the dimensions of followership styles?" The study strives to understand the dimensions of followership styles in relation to congregational leaders as followers in the context of the Korean American church. This study focused on two central research questions. Therefore, the Followership Questionnaire by Kelley (1992), was employed to measure the followership behaviors and styles. The data were collected from five Korean churches, and data were analyzed through analysis of variance (ANOVA) and post-hoc tests. The finding supported the first research hypothesis that if the responsibilities of church officers increased the followership questionnaire scores of those leaders would also increase. For that second hypothesis, that specific characteristics of the participants had a significant effect on the dimensions of followership style the results showed that for church leaders, the independent thinking dimension was significantly affected by age and language but not gender (Chai, 2010). Also, the active engagement dimension was significantly affected by age but not by gender or language. This research provides evidence of followership as an essential element of leadership development in the Korean American church.

Kuepers's (2011) study shows a comprehensive understanding of the multidimensional, ambivalent and responsive process of transformation, particularly as related to non-cognitive processes and effects of leader- and followership. Based on critical literature review, advanced phenomenology and a relational approach, the significance of form and embodied, emotional and aesthetic dimensions, potential and effects of transforming in general and transformational leadership in particular are discussed. Findings from this study reveal that transformations in organizations are recognized as an embodied, emotional and aesthetical as well as inter-relational event. With an extended understanding, Kuepers (2011) emphasizes that transformational leadership can be transformed into an aesthetically informed and more integral practice of leader and followership. Thus, the study contributes to an innovative comprehension and offers critical perspectives on transformative processes creative transformation of conventional understandings and practices of leader and followership in organizations.

Finally, a research on the concept called leader's implicit followership theories (LIFTs), which can be defined as leaders' pre- 
existing beliefs about followers' personal attributes and characteristics, was conducted by Kedharnath (2011). The goal of this study was to address the impact of LIFTs on employee outcomes. Besides, LIFTs are specifically hypothesized to influence the relationship between supervisors (leaders) and their employees (followers). Employees' perception of this relationship was hypothesized to influence employee outcomes namely, employee job satisfaction and organizational commitment. Kedharnath's (2011) findings show that LIFTs did not predict employees' perceptions of the relationship with their supervisor, while employees' perceptions of the relationship predicted job satisfaction and organizational commitment.

\section{The Present Study}

Considering the above developments, the purpose of this study was to: 1) investigate if the followership styles as proposed by Kelley (1992) are represented in the followership styles of the secondary and primary school teachers in Adni Islamic School (AIS); 2) investigate which of Kelley's (1992) followership styles are most practiced by the secondary and primary school teachers of AIS; 3) examine if there are significant differences in followership styles between the male secondary and primary school teachers of AIS; 4) examine if there are any significant differences in followership styles between the female secondary and primary school teachers of AIS; and 5) examine if there are significant differences in followership styles between the secondary and primary school teachers of AIS in general.

To achieve those objectives, the study sought answers for the following research questions: 1) Do the followership styles proposed by Kelley (1992) represent the followership styles of the secondary and primary school teachers in AIS? 2) Which of Kelley's (1992) followership styles are most practiced by the secondary and primary school teachers of AIS? 3) Is there any significant difference in followership styles between the male secondary and primary school teachers of AIS? 4) Is there any significant difference in followership styles between the female secondary and primary school teachers of AIS? 5)Is there any significant difference in followership styles between the secondary and primary school teachers of AIS in general? 


\section{Method}

This research is survey-oriented, whereby the researcher employed a quantitative method. The quantitative method is defined as a type of educational research in which the researcher decides what to study, ask specific, narrow questions, collects quantifiable data from participants, analyzes these numbers using statistics, and conduct the enquiry in an unbiased, objective manner (Creswell, 2008: 45). Moreover, quantitative statistics is utilized as a way to determine the variables.

This study used the quantitative method because it's main advantages are time and cost efficient. Other advantages are: (i) the ability to generalize the results from the sample to the population of interest; (ii) large numbers of representative cases; and (iii) the data collection method is uniform and hence guarantees the anonymity of the respondents (Malhotra, 2004).

\section{Population and Sampling}

The population can be defined as a group of individuals who have similar characteristics (Creswell, 2008). According to Johnson and Christensen (2004), a sample is a set of elements taken from a larger population according to certain rules. The population of the study consisted of 127 teachers from both primary and secondary school of AIS. Based on Krejcie and Morgan (1970), the sample size for this study is 92 . The respondents were selected through a simple random sampling technique. Simple random sampling is a procedure which provides equal opportunity of selection for each element in the population (Moore \& McCabe, 1999). The "draw lot" techniques was used where a symbol of each unit of the population was placed in a container, mixed and 'lucky numbers' were drawn to constitute the sample. Although simple random sampling is laborious and is not usually the most convenient sampling method (Babbie, 1973), it is the most convenient method because every element or number of the population had equal chances of being selected.Since the population is over 100 persons, the researcher is allowed to take $10 \%-15 \%$ or $20 \%-25 \%$ or more as a sample of the study (Ary, Jacobs \& Razavieh, 1996).

\section{Research Instrumentation}

The Followership Questionnaire (TFQ) by Kelley (1992) was adopted in this study. The survey questionnaire comprised 20 items and was 
divided into two sections. In Section One, the respondents were asked to answer the questions on gender, age and years of teaching. The purpose of these demographic questions was to provide descriptions of the sample. Section Two was on independent thinking and active engagement.

All items for Section Two useda 7-point Likert Scale. The participants responded to the items on the questionnaire by checking one out of seven points ranging from $1=$ Rarely to $7=$ Almost Always. The scores were tabulated and then the identification of followership styles was based on where the scores fell on the $\mathrm{Y}$ axis for independent thinking on the $\mathrm{X}$ axis for active engagement. Those with exemplary followership tend to score high in the areas of independent thinking and active engagement. Individuals with alienated followership tend to score high in the areas of independent thinking and low in active engagement while conformists tend to score high in the areas of active engagement but low in independent thinking. Those with passive followership tend to score low in both independent thinking and active engagement while pragmatists tend to have centrist scores in both independent thinking and active engagement.

\section{Findings and Discussion}

Descriptive statistics were used to answer the first research question. McMillan and Schumacher (1993) state that descriptive statistics transforms a set of numbers or observations into indices that describe or characterize the data. So, for the first research question, the study used descriptive statistics to examine the distribution of mean and standard deviation and the percentage of teachers' preference of each followership style (Kelley, 1992) that represented the followership style of secondary and primary school teachers of AIS.

Descriptive statistics were also used to answer the second research question. By using the descriptive statistics to examine the distribution of mean and standard deviation and the percentage, the followership styles of Kelley (1992) practiced by the secondary and primary school teachers of AIS could be found.

Independent sample t-tests were used to answer the third, fourth and fifth research questions. Independent t-test was used to compare the means from two different groups. Brown (1990) states that two 
assumptions should be there in conducting the t-test. The assumptions underlying the t-test are the normality distribution of the score in each group and homogeneity of variance for the score of two groups.

Table 1 provides information about the followership styles of all the , respondents. Frequency and percentage were used to identify the teachers' followership styles. The majority $(42.3 \%)$ of the participants acted as exemplary follower, $26.1 \%$ of the participants acted as alienated follower, $16.3 \%$ of them acted as conformist followers, $8.7 \%$ of them were passive followers and $6.5 \%$ were alienated followers.

Table 1: The Percentage Rank of Followership Style for Respondents $(\mathrm{N}=92)$

\begin{tabular}{|c|l|l|}
\hline $\begin{array}{c}\text { Followership } \\
\text { styles }\end{array}$ & Percentage (\%) & N \\
\hline Exemplary & 42.3 & 39 \\
\hline Pragmatist & 26.1 & 24 \\
\hline Conformist & 16.3 & 15 \\
\hline Passive & 8.7 & 8 \\
\hline Alienated & 6.5 & 6 \\
\hline Total & $100 \%$ & 92 \\
\hline
\end{tabular}

The first research question was: Do the followership styles proposed by Kelley (1992) represent the followership styles of the secondary and primary school teachers in AIS? The answer to this question is that the followership styles proposed by Kelley (1992) do represent the followership styles of the secondary and primary school teachers in AIS.

The second research question was: Which of Kelley's (1992) followership styles are most practiced by the secondary and primary school teachers of AIS? The answer to this question is that the Kelley's exemplary followership style (1992) was most practiced by the secondary and primary school teachers of AIS. 
Table 2: Independent T-Test Result ( $\mathrm{N}=92)$

\begin{tabular}{|l|l|l|l|l|l|l|l|}
\hline $\begin{array}{l}\text { Vari- } \\
\text { able }\end{array}$ & $\begin{array}{l}\text { Re- } \\
\text { spond- } \\
\text { ent }\end{array}$ & $\mathrm{N}$ & Mean & SD & $\mathrm{t}$ & Df & $\mathrm{P}$. \\
\hline $\begin{array}{l}\text { Fol- } \\
\text { lower- } \\
\text { ship } \\
\text { Style }\end{array}$ & $\begin{array}{l}\text { Male } \\
\text { Pri- } \\
\text { mary }\end{array}$ & 11 & 93.27 & 9.37 & $-1.399-$ & 27 & .020 \\
\cline { 2 - 8 } & $\begin{array}{l}\text { Male } \\
\text { Sec- } \\
\text { ondary }\end{array}$ & 18 & 1.018 & 18.8 & $-1.627-$ & & \\
\hline
\end{tabular}

$\alpha=0.05$

The third question was: Is there any significant difference of followership styles between the secondary and primary male school teachers of AIS? In addressing this question, the following hypotheses were generated:

Ho: There is no significant difference between followership styles of the secondary and primary male school teachers of AIS.

Ha: There is significant difference between followership styles of the secondary and primary male school teachers of AIS.

In response to the second question, Table 2 exhibits the independent $\mathrm{t}$-test for the male secondary and primary school teachers of AIS. The data analysis indicated that the mean scores of male teachers of primary $(\mathrm{M}=93.27, \mathrm{SD}=9.37)$ and that of male teachers of secondary $(\mathrm{M}=1.018, \mathrm{SD}=18.8)$, indicated that there is a significant difference between these two groups, $\mathrm{t}=.020, \mathrm{p}<.05$. Therefore, the null hypothesis (Ho) was rejected and the alternative hypothesis is accepted. Hence, it is concluded that there was a significant difference in the level of followership style among male teachers in the primary and secondary schools of AIS.

The fourth question was: Is there any significant difference of followership styles between the secondary and primary female school teachers of AIS? In addressing this question, the following hypotheses were generated: 
Ho: There is no significant difference of followership styles between the secondary and primary female school teachers of AIS.

Ha: There is significant difference of followership styles between the secondary and primary female school teachers of AIS.

Table 3: Independent T-Test Result ( $\mathrm{N}=92)$

\begin{tabular}{|l|l|l|l|l|l|l|l|}
\hline $\begin{array}{l}\text { Vari- } \\
\text { able }\end{array}$ & $\begin{array}{l}\text { Re- } \\
\text { spond- } \\
\text { ent }\end{array}$ & $\mathrm{N}$ & Mean & SD & $\mathrm{t}$ & Df & $\mathrm{P}$. \\
\hline $\begin{array}{l}\text { Fol- } \\
\text { lower- } \\
\text { ship } \\
\text { Style }\end{array}$ & $\begin{array}{l}\text { Male } \\
\text { Pri- } \\
\text { mary }\end{array}$ & 11 & 93.27 & 9.37 & $-1.399-$ & 27 & .020 \\
\cline { 2 - 8 } & $\begin{array}{l}\text { Male } \\
\text { Sec- } \\
\text { ondary }\end{array}$ & 18 & 1.018 & 18.8 & $-1.627-$ & & \\
\hline
\end{tabular}

$\alpha=0.05$

Table 3 shows an independent t-test to compare the followership styles between female secondary and primary school teachers of AIS. The data indicated that the mean scores of female teachers of primary $(\mathrm{M}=1.035, \mathrm{SD}=14.71)$ and that of the female teachers of secondary $(\mathrm{M}=1.027, \mathrm{SD}=13.68)$, indicated that there is no significant difference between these two groups, $\mathrm{p}=.748, \mathrm{p}>.05$. Therefore, the null hypothesis (Ho) was accepted and the alternative hypothesis is rejected. Hence, it is concluded that there was no significant difference in the level of followership style among female teachers in the primary and secondary schools of AIS.

The fifth question was: Is there any significant difference of followership styles between the secondary and primary school teachers of AIS in general? In addressing this question, the following hypotheses were generated:

Ho: There is no significant difference of followership styles between the secondary and primary school teachers of AIS.

Ha: There is significant difference of followership styles between the secondary and primary school teachers of AIS. 
Table 4: Independent T-Test Result ( $\mathrm{N}=92)$

\begin{tabular}{|l|l|l|l|l|l|l|l|}
\hline $\begin{array}{l}\text { Vari- } \\
\text { able }\end{array}$ & $\begin{array}{l}\text { Re- } \\
\text { spond- } \\
\text { ent }\end{array}$ & N & Mean & SD & $\mathrm{t}$ & Df & P. \\
\hline $\begin{array}{l}\text { Fol- } \\
\text { lower- } \\
\text { ship } \\
\text { Style }\end{array}$ & $\begin{array}{l}\text { Female } \\
\text { Pri- } \\
\text { mary } \\
\text { Teach- } \\
\text { ers }\end{array}$ & 42 & 1.035 & 14.71 & .192 & 61 & .748 \\
\cline { 2 - 7 } & $\begin{array}{l}\text { Female } \\
\text { Sec- } \\
\text { ondary } \\
\text { Teach- } \\
\text { ers }\end{array}$ & 21 & 1.027 & 13.68 & .197 & & \\
\hline
\end{tabular}

$\alpha=0.05$

The data as shown in Table 4 indicated that the mean score of primary teachers $(\mathrm{M}=1.013, \mathrm{SD}=14.32)$ and that of secondary teachers $(\mathrm{M}=1.023, \mathrm{SD}=16.04)$, the data indicates that there is no significant difference between these two groups, $\mathrm{p}=.288, \mathrm{p}>.05$. It is concluded that there was no significant difference in the followership style among teachers in the primary and secondary schools of AIS.

The research findings of this study are discussed based on the followership style characteristics practiced at the AIS. The data obtained from this study were analyzed using demographic data of respondents and the results show that most teachers of AIS agreed on the "independent thinking" and "active engagement" characteristics of followership styles. Hence, the followership styles as proposed by Kelley (1992) are represented in the school teachers at AIS. According to Ricketson (2008), the followership styles through thinking and behaviour, independently or dependently, passive or active can be observed in a school environment. However, Burke (2009) suggested a strong association between followership style and leadership style, followership behaviour, individual variables, organizational cultures, and institutional variables used to promote quality in the school. 
With regard to another finding, the followership style most practised by the school teachers of AIS was "exemplary" rather than "pragmatist", "conformist", "passive" or "alienated". The finding supports the study by Chai (2010) who wanted to understand the dimensions of followership styles among Korean American church members in the USA. The dimensions of followership style were increased when responsibilities of environment and leader increased, especially the exemplary dimension. This research provides evidence of exemplary characteristic as an essential element of followership style to develop high quality institutions. According to Carsten, et al. (2010), the major characteristics of the followership style are obedience, expressing opinions, and taking initiatives between groups of followers. Thus, the result also revealed that contextual factors may affect both followership constructions and behaviour in the follower roles.

The third finding was the gap in followership style between the male primary and secondary school teachers of AIS. The finding shows that male primary and secondary teachers had different conditions of followership style. The researcher found many factors which could have contributed to the differences in this finding; 1) the size of the population; if the sample had been increased, the more precise it will be in the estimation of the population; 2) the environment and leader conditions, whereby the male teachers of the secondary school were coming from different backgrounds and cultures. This finding contradicted Chai's (2010) which states that followership styles are significantly affected by age and language but not gender. Therefore, the implications of this finding cannot be generalized into different conditions and cultures.

The fourth finding of this study concerns the gender analysis of followership styles among female secondary and primary school teachers of AIS. There was no significant difference between these two groups, perhaps because of several factors such as culture, environment of the job, and leadership style. The culture and environment of the job in the school was comfortable for all the teachers, especially for the female teachers. According to Barth (2003), followership styles and environment have positive relationships with behaviour characteristics of employees at an organization. Leadership styles also have significant relations with followership behaviour (Colangelo, 2000) especially in active engagement, critical, independent thinking, passion, and team mindedness. The study by Mertler (1997) concludes that the female 
teachers of California and Ohio schools were reported to have a higher level of followership style than the male teachers. This is sufficient evidence to believe that female teachers are more likely to adapt to this type of environment than the male teachers.

Finally, the finding shows that there was no significant difference of followership style between secondary and primary school teachers of AIS in general. Likewise studies done by VanDoren (1998), Steyer (2001), and Beckerleg (2002), examined the differences of followership style in different organizational settings such as schools, hospitals, home care, and banks, and most of the results show that there were no significant differences between two organizations on followership style. Thus, this study corroborates the result of previous research conducted in different organizations.

\section{Theoretical Implications}

School members who engage in the running of the school consist of 'leaders' and 'followers', comprising school staff, teachers and students. The school environment containing leadership style and followership style provides the impetus and framework for school improvement.

In terms of theoretical implications, followership style is the ultimate willingness of others (personal) to go along with the subordinate leader in an organization (Ricketts, 2009). Followership as a group in one goal relations play effective roles in the success of the group leader's functioning in an organization. In this research, the teachers are delegated with the responsibilities to assess the school performance by using the followership style theory. Regardless of the approach, teachers should know and understand the essential importance of followership roles in schools. Ultimately, the aim is to build relationships and task with other members of the school so that they can achieve greatness. This study sought to extend the body of knowledge around followership, especially, operationalizing courageous followership theory.

Therefore, the school principals (primary or secondary) describe the teachers' ability to change their followership style based on the readiness of the teachers (Kuepers, 2011). The study contributes to an improved understanding and offers a critical perspective on transformative processes of conventional perspectives and practices of leader and followership in the school. 


\section{Practical Implications}

This research also contributes to the practice as it provides valuable information that can be used to increase the extent to which followership style could be significantly used to measure the readiness of the followers. Followership characteristics give practical situational knowledge of school teachers' understanding and practicing of followership styles. By combining different amounts of task behaviour with different amounts of relationship behaviour, an effective leader may use different followership styles (Carsten et al., 2010). Even though teachers' skills and motivations are varied with time and scope, followership style suggests that leaders should change the degree according to the level of members' maturity.

Moreover, another implication of utilizing this theory is the extent to which followership style is relevant to school excellence and school achievement. Lastly, teachers have the opportunity to express their feelings to the school principals. These reflect the true picture that it is the followers who accept or reject the leader based on two followership dimensions: independent thinking and active engagement (Kelley, 1992). Consequently, teachers and school principals are the key players to achieving excellence in schools.

\section{Conclusion}

This study is unique and timely, to the best knowledge of the researcher. Followership study is important in the field of leadership and its basic concept is imperative for organizational leaders to understand. Hence, it is important to conduct studies on one dimension of followership in an educational institution. The current study provides an insight into the gap between primary and secondary school teachers in their followership style as proposed by Kelley (1992) at AIS, Malaysia. Moreover, the findings from this study will add to the existing literature on educational management and leadership. On the other hand, this study will also contribute to the organizational performance at AIS.

Findings from the present study are extensively based on Kelley's (1992) conceptual framework that contains the constructs investigated on followership styles practiced by the teachers. Therefore, the followership styles of Kelley (1992) have been found to be practiced by 
school teachers of AIS regardless of their gender, teaching experience and school qualification. Based on the foregoing, exemplary followership styles have been practiced by the teachers at AIS. Therefore, leaders must foster organizational cultures that horizontally integrate the attributes from the bottom up and must also understand that exemplary followers will be necessary for maintaining positive behaviour in the overall organizational performance for school development. Finally, such significant differences of followership styles have existed within the primary and secondary teachers at AIS. As a model, the teachers must be ready to complement one another in promoting teachers' development and demonstrate full-fledged professionalism as an integral part of the school educational development plan.

\section{References}

Adni, (2008). About Adni Islamic school. Retrieved September 22, 2011. http:// siadni. blogspot.com/2008/03/about-our-school.html.

Alcorn, D. S. (1992). Dynamic followership: Empowerment at work. Management Quarterly (33), pp. 9-13.

Aliabadizadeh, S. (2009). An examination of followership traits in Iranian small firm 's performance. Master Degree Theses. The College of Business. University Utara Malaysia.

Ary, D., Jacobs, L. C., \& Razavieh, A. (1996). Introduction to Research in Education (7th edn.). Belmont, CA: Wadsworth/Thomson.

Babbie, E. R. (1973). Survey Research Methods Belmont. Wadsworth Publishing Company Incorporated, California.

Barth, J. A. (2003). Followership preferences for gender based leadership characteristics in the virtual environment. Doctoral Degree Thesis. School of Education. Colorado State University Fort Collins, Colorado.

Bass, B. M., \& Avolio, B. (1995). MLQ: Multifactor leadership questionnaire sampler set and technical report. Redwood City, CA: Mind Garden.

Beckerleg, C. N. (2002). An exploration of the practice of followership. Doctoral Degree Dissertation. The Faculty of the Graduate School. University of Minnesota.

Bennis, W. (2008). Introduction. In Ronald E. Riggio, Ira Chaleff \& Jean Lipman-Blumen, The Art of Followership: How Great Followers Create Great Leaders and Organizations. San Francisco: Jossey-Bass Wiley Imprint Publication.

Bresnen, M. (1995). All things to all people: Perceptions, attributions, and constructions of leadership, The Leadership Quarterly 6 (4), pp. 495-513. 
Brown, L. D. (1990). An ancillarity paradox which appears in multiple regression models. Ann. Statist. 18, pp. 471-538.

Brumm, C. A. (2010). Leadership that enables: how long-term planning relates to followership. Master Degree Thesis. Graduate Studies in Leadership and the College of Adult and Professional Studies. Indiana Wesleyan University.

Bryman, A. (1986 ) Leadership and Organizations, Routledge, London.

Burke, L. M. (2009). Correlations of followership and leadership styles of medical science liaisons within the pharmaceutical and biopharmaceutical industry. Doctoral Degree Dissertation. Department of Philosophy. Capella University.

Carsten, M. K.; Uhl-Bien, Mary; West, Bradley, J.; Patera, Jaime, L., McGregor, \& Rob (2010). Exploring social constructions of followership: A qualitative study. Leadership Institute Faculty Publications. Paper 20.

Chai, D. H. (2010). Leading as followers: A followership study of the Korean congregational leadership of the presbyterian church (U.S.A.). Doctoral Degree Dissertation. Leadership Education. Spalding University. Louisville, KY.

Chaleff, I. (2009). The Courageous Follower: Standing Up to and for Our Leaders. (3rd edn.). Berrett-Koehler Publishers. San Francisco, CA.

Colangelo, A. J. (2000). Followership: Leadership styles (Doctoral dissertation, The University of Oklahoma,. Dissertation Abstracts International, 61(05), 1934.

Collinson, D. (2006). Rethinking followership: A post-structuralist analysis of follower identities. Leadership Quarterly, 17(2), pp. 179-189.

Creswell, J. W. (2008). Educational Research: Planning, Conducting, and Evaluating Qualitative and Quantitative Research. (3rd edn). New Jersey: Pearson Education.

Cross, R., \& Parker, A. (2004). The Hidden Power of Social Networks. Boston: Harvard Business School Publishing.

Curphy, G. (2005). Followership: turning stakeholders into advocates. Curphy Consulting Corporation, Dewhurst.

Defee, C. C. (2010). Performance implications of transformational supply chain leadership and followership. International Journal of Physical Distribution \& Logistics Management. Vol. 40 No. 10, 2010. pp. 763-791.

Dixon, E. N. (2003). An exploration of the relationship of organizational level and measures of follower behavior. Doctoral Degree Dissertation. University of Alabama in Huntsville. 
Donald, O. Y. (2010). A Study of followership within critical care environment. Monarch Business School University for Graduate Studies in Management. Grint, K. (2000). The Arts of Leadership. Oxford: Oxford University Press.

Havins, J. H. (2010). An examination of the relationship of organizational levels and followership behaviors in law enforcement. Doctoral Degree Dissertation. Educational Leadership. Northern Arizona University.

Heremuru, S. G. (2008). A symbiotic relationship between leaders and followers. Retrieved September 24, 2011. http://ezinearticles.com/?ASymbiotic-Relationship-Between-Leaders-and-Followers\&id=1299700

John, M. O. (2010). Time to focus on Followers: Looking at the other side of the Leadership 'coin', Academic Leadership The online Journal, 8 (4), pp. $1-3$.

Johnson, B., \& L. Christensen (2004). Educational Research: Quantitative, Qualitative, and Mixed Approaches. (2nd edn.). Boston, MA: Pearson Education.

Kedharnath, U. (2011). The influence of leaders' implicit followership theories on employee outcomes. Master Degree Thesis. Department of Psychology. Colorado State University.

Kelley, R. E. (1992). The Power of Followership. New York: Doubleday.

Kellerman, B. (2008). Followership: How Followers Are Creating Change and Changing Leaders. Harvard Business Press, Boston, USA.

Krejcie, R. V., \& Morgan, D. W. (1970). Educational and psychological measurement. National Education Association.

Kuepers, W. M. (2011). Leader- and followership as an embodied, emotional and aesthetic practice for creative transformation in organizations. Leadership \& Organization Development Journal. Vol. 32, 1 pp. 20 - 40.

Malhotra, N. K. (2004). Marketing research: An applied orientation (4th edn.). Upper Saddle River, NJ: Prentice Hall.

McMillan, J. H., Schumacher, S. (1993) Research in Education a Conceptual Introduction (3rd edn). New York: Harper Collins College Publishers.

Mertler, C. A. (1997). Teachers'Perceptions of the Leadership /Followership Dialectic. Doctoral Degree Dissertation. Department of Educational Foundations and Enquiry Bowling. Green State University.

Moore, D. S., \& McCabe, G. P. (1999). Introduction to the Practice of Statistics, (3rd edn). New York.

Notgrass, D. P. (2010). The relationship between followers 'perceived quality of relationship and preferred leadership style. Doctoral Degree Dissertation. Dallas Baptist University. 
Pitron, J. (2008). Followership is leadership: The leadership-exemplary followership exchange model. Retrieved September 24, 2011. http://knol. google.com/k/ followership-is-leadership\#.

Ricketson, R. S. (2008). An Exploration of the Relationship of Leadership Styles and Dimensions of Courageous Followership. Doctoral Degree Dissertation. School of Global Leadership and Entrepreneurship. Regent University.

Ricketts, K. G. (2009). Empowering Leader in Kentucky (ELKI-2005). University of Kentucky College of Agriculture, Lexington.

Sergiovanni, T. J. (1996). Leadership for the schoolhouse: How is it different? Why is it important San Francisco: Jossey-Bass.

Smircich, L., \& Morgan, G. (1982) L. Leadership: The management of meaning. Journal of Applied Behavioral Science, 18 pp. 257-273.

Smith, J. S. (2009). Followership behaviors among Florida community college faculty. Doctoral Thesis Dissertation. Graduate School of the University of Florida

Steyer, S. (2001). An examination of public school teachers perceptions offolio wership through the refinement of the teacher sentiment inventory. Doctoral Degree Theses. Graduate College of Bowling Green State University.

VanDoren, E. S. (1998). The relationship between leadership and followersip in staff nurses and employment setting. Doctoral Degree Thesis. Faculty of The Graduate College. Department of Educational Leadership. Western Michigan University Kalamazoo, Michigan.

Williams, G. A., \& Miller, R. B. (2002). Change the way you persuade. Harvard Business Review, 80, 65-73.

Wonders, G. F. (1996). Followership and Leadership in Nursing. Master Degree Theses. The Faculty of Pacific Lutheran University.

Ye, Y. (2008). Factors relating to teachers' followership In International Univeristies in Thailand. Master Degree Theses. Graduate School of Education Assumption University of Thailand. 